\title{
Fundamentos y evolución de la pedagogía preventiva sobre la muerte a través de la filosofía
}

\author{
ANABEL RAMOS-PLA* \\ Universidad de Lérida - España \\ Recibido el 22-02-19; primera evaluación el 02-12-19; \\ segunda evaluación el 20-12-19; tercera evaluación el \\ 22-01-20; aceptado el 04-02-20
}

\section{RESUMEN}

En este ensayo pretendemos abordar la historia del pensamiento filosófico como base y pilar fundamental de la pedagogía preventiva o previa sobre la muerte. En el escrito, se conceptualizará y contextualizará al lector sobre qué supone la educación preventiva sobre la muerte; no como ámbito escolar, sino como meta en el desarrollo humano. Con ello, se llevará a cabo un análisis de las diferentes visiones y de la situación actual tanto desde la perspectiva filosófica como pedagógica.

Palabras clave: muerte, educación y filosofía, innovaciones educativas, filosofía de la educación.

Foundations and Evolution of Preventive Education on death through the Philosophy

\section{Abstract}

In this assay, we address the history of philosophical thought as the basis and cornerstone of preventive or previous education about death. In the article, conceptualises and contextualizes in the behalf of the reader about what constitutes death prevention education, not as a school setting, but as a goal in human development. This is intended to make an analysis of the different visions and the current situation both from the philosophical and pedagogical perspective.

Keywords: death, education and philosophy, educational innovations, education philosophy.

\footnotetext{
* Profesora de la Universidad de Lérida (Universitat de Lleida), Espańa. Doctora en Educación por la Universidad Autónoma de Barcelona. Maestra de Educación Primaria en actividad. Psicopedagoga, colaboradora y técnica en Investigación de la Universidad de Lérida. Sus principales líneas de investigación están relacionadas con la pedagogía de la muerte y la innovación en las metodologías docentes. Correo electrónico: anabel.ramos@udl.cat
} 
Fundamentos e evoluçáo da Pedagogia Preventiva sobre a morte por meio da Filosofia

\section{Resumo}

Neste ensaio, pretendemos abordar a história do pensamento filosófico como base e pilar fundamental da pedagogia preventiva ou anterior sobre a morte. No artigo, o leitor será conceituado e contextualizado sobre o que supóe a educação preventiva sobre a morte; não como um ambiente escolar, mas como um objetivo no desenvolvimento humano. Pretende-se fazer uma análise das diferentes visões e da situação atual, tanto do ponto de vista filosófico quanto pedagógico.

Palavras-chave: morte, educação e filosofia, inovaçóes educacionais, filosofia da educação. 


\section{INTRODUCCIÓN}

Durante la última década, se ha llevado a cabo bastante investigación sobre la pedagogía de la muerte. El motivo clave, por el cual existe una proliferación de investigaciones en relación con la temática que nos ocupa, es la necesidad de la inclusión de la muerte en los centros escolares. Además, se debería hacer más hincapié en la pedagogía preventiva o previa (Herrán, González, Navarro, Freire y Bravo, 2000) sobre la muerte, ya que posibilita la adquisición de estrategias para afrontar futuras situaciones de muerte y duelo, así como la normalización de la situación. Asimismo, es necesaria la reflexión sobre las bases de la pedagogía preventiva sobre la muerte, ya que no provienen del ámbito educativo, sino de una materia muy similar: la filosofía. Esta disciplina fue quien empezó a pensar en la muerte y en su pedagogía, así como en publicar y expandir dicha idea.

\section{Desarrollo}

\subsection{Definición de pedagogía preventiva o previa sobre la muerte}

En primer lugar, no existe una «pedagogía preventiva sobre la muerte». Es necesario, por tanto, empezar por definir tanto el concepto como la necesidad de esta. Este ámbito pedagógico se centra en la educación de la muerte, teniendo como base y objetivo la normalización de la muerte (Arnaiz, 2003; Asensi, 2012; Head y Smith, 2016; Girardi, San Gil y Santillán, 2009; Herrán y Cortina, 2007; Herrán, González, Navarro, Freire y Bravo, 2000; Herrán, González, Navarro, Bravo y Freire, 2001; Poch, 2009 nos han precedido en la definición y el objetivo) para favorecer la formación integral de las personas. Asimismo, compartimos el argumento de Huisman-Perrin (2003), quien entiende el diálogo con la muerte desde una perspectiva en la cual hay que "considerarla sin empequeñecerla, medirla sin minimizarla, evocarla con precisión sin dilucidarla, no es ni entenderla ni explicarla propiamente dicho, tareas racionalmente imposibles, sino que es escucharla o domesticarla para evitar el horror y el miedo» (Huisman-Perrin, 2003, p. 11).

La pedagogía de la muerte preventiva o previa (Herrán, González, Navarro, Freire y Bravo, 2000) se refiere a la educación propia y de los otros (por ejemplo, alumnos) anterior a un fallecimiento significativo de alguien cercano. Por eso, es necesaria la toma de conciencia sobre la muerte, ya que nos hace cuestionar y reflexionar sobre todo aquello que queremos hacer durante el tiempo que tenemos (Orellán, 2003; Poch, 2009), reconsiderar 
—o considerar por primera vez- la vida (Aracil, 1998) y, por último, se favorece la superación positiva de las pérdidas que se hayan sufrido a lo largo de la vida (Castro y Chinchilla, 1997; Colomo, 2016).

Entendemos por finitud la definición realizada por Mèlich (2011), quién escribió que somos seres que estamos realizando un trayecto vital dentro de un espacio y tiempo, y añade que "la finitud es sinónimo de vida» (Mèlich, 2011, p. 15). El filósofo apuesta, y en esto estamos completamente de acuerdo, por la plena conciencia de la muerte mientras el humano está vivo, pero que no somos «ser-para-a-la-muerte» (Heidegger, 1927), sino que estamos hic et nunc para empezar algo nuevo; nuestra vida, la cual será única e intransferible. De este modo, apostamos por el aprendizaje del tiempo y no solo en el tiempo. Por lo tanto, la muerte es el final del trayecto de la vida, el cual acuñó el nombre de finitud. En esto consiste la diferencia entre muerte y finitud. Mèlich (2011) entiende la muerte como condicionante de la finitud, no como parte de la vida. Empero, nos oponemos en parte a la tesis de Mèlich, dado que la muerte es condición intrínseca de la finitud, porque forma parte de la vida. Si no formara parte de la vida, la muerte no supondría ningún tipo de condicionante de la finitud.

Hay que añadir que a través de la pedagogía preventiva sobre la muerte se pretende tratar la muerte con normalidad, hablando sobre ella anticipadamente para poder crecer internamente y, así, poder estar preparados para su llegada (Aracil, 1998; Cantero, 2013; Dolto, 2005; Gabarró, 2016; Girardi, San Gil y Santillán, 2009; Kübler-Ross, 2013; Mantegazza, 2006; Sáiz Ripoll, 2010; Valenzano, 2015). De esta forma, pretendemos prepararnos en el sentido existencial, mediante la toma de conciencia de la existencia de la muerte. En consecuencia, nos estaremos preparando tanto para afrontar el duelo como para superar los miedos que rodean la muerte (Cantero, 2013; Guillén et al. 2013). Herrán y Cortina (2006) añaden que el desarrollo educativo de una educación para la muerte debe alargarse a lo largo de la vida, mediante la educación familiar, infantil, primaria, secundaria y universitaria. Por todo ello, coincidimos en la afirmación de Rodríguez, Herrán y Cortina (2015) de que se debe introducir la pedagogía de la muerte en el currículum escolar, como tema radical, dentro de una tercera dimensión curricular, además de la disciplinar (áreas de conocimiento y asignaturas) y transversal (competencias y temas transversales).

Conocer las emociones y hechos que desencadena la muerte de un ser querido posibilita una elaboración del duelo de forma más positiva. De este modo, partiendo de la conciencia de la finitud humana, se puede aprender de la importancia del carpe diem para, así, vivir con más plenitud, energía 
e ímpetu - aquello que Schopenhauer denominó voluntad- (Cathcart y Klein, 2012; Mèlich, 2008). Bermejo (2003, pp. 124-125) sostuvo que este hecho nos aporta tres aprendizajes clave:

- Valorar lo que tenemos. En esta línea, Cabodevilla (citado por Poch, 2006) cuestiona nuestra mínima capacidad de valorar aquello que somos y tenemos.

- Alejar preocupaciones y deseos triviales.

- Autoconsciencia que la propia existencia no se puede posponer («no dejar para mañana lo que puedes hacer hoy»).

En definitiva, desde esta perspectiva y tal y como apunta Kübler-Ross (2013, p. 40), «morir no es, necesariamente, un asunto triste y terrible [...] la muerte puede ser tan simple y poco complicada como lo es la vida, si no la convertimos en una pesadilla». Los ciudadanos de las culturas occidentales no estamos preparados ni hemos recibido ningún tipo de preparación para recibir la muerte como algo normalizado (Marinoff, 1999). Por lo tanto, es una urgencia social y humana recibir más formación pedagógica y filosófica sobre la finitud, la muerte y el duelo. Apostamos por la pedagogía preventiva sobre la muerte abordada desde diferentes ámbitos del conocimiento, de los cuales destacamos la importancia de la fundamentación filosófica.

\subsection{Arqueología de la pedagogía preventiva o previa sobre la muerte. Bases filosóficas}

Actualmente, permanecen diferentes teorías y creencias de las cuales no sabemos su origen. Empero, si se busca su etimología, nos podemos sorprender de los orígenes e inicios de la cuestión que nos ocupa. Respecto a la pedagogía preventiva sobre la muerte, la filosofía nos ayuda a comprender la realidad humana y, sobre todo, los orígenes clave de la filosofía de la muerte. En este sentido, las preguntas fundamentales de la filosofía están ligadas con la mortalidad humana (Cathcart y Klein, 2012, pp. 10-11): «¿Qué sentido tiene la vida? ¿Cómo tendría que afectar la conciencia de la muerte a la forma de vivir? ¿La vida tendría un significado diferente si se viviera eternamente? ¿Tenemos alma, y si es así, sobrevivirá al cuerpo? ».

La gran mayoría de los grandes pensadores han reflexionado sobre la muerte y la finitud, dado que es la realidad más segura que conoce el ser humano (Esquerda y Agustí, 2010, Mèlich, 2008). En nuestro caso, el origen de la pedagogía sobre la muerte se puede encontrar en los filósofos del siglo IV a. C., 
aunque podemos encontrar sus bases en los filósofos estoicos (siglo III a. C.) como posteriormente destacó Séneca, perteneciente al siglo I d. C. Si bien es cierto que no empleaban el concepto como tal, sí que le buscaban razonamientos empleando el diálogo y el debate. El ejemplo más claro y definido de todos nos lo proporciona Platón en su Fedón, donde intermediando un diálogo emocionante con Equécrates narra los momentos previos a la muerte de su maestro, Sócrates. Es aquí donde encontramos los inicios más evidentes de una pedagogía de la muerte. En aquella época, todavía no se hablaba de la pedagogía en sí, empleando el concepto, pero sí que se daban diferentes nociones de la educación, el conocimiento y las metodologías de aprendizaje. En la misma línea, Pascual (2008) afirma que el tema de la educación ocupa un lugar central en el Fedón de Platón.

En el Fedón, Platón (de ahora en adelante Fedón) explica cómo se encontraban todos los discípulos y su maestro en la celda donde moriría tras beber la cicuta. Sócrates fue encarcelado, juzgado y condenado a morir por los atenienses de la época. Es aquí donde Platón, mediante el personaje de Sócrates, expone sus ideas sobre la muerte y todo lo que comporta, haciéndose responsable de la misma. El filósofo empieza su apología alegando que la muerte es la separación del cuerpo del alma y, además, apuesta por la inmortalidad de esta última.

Desde el primer momento, se nos presenta un Sócrates sereno, sonriente, tranquilo y animado, hecho que sorprende a sus discípulos, dado que su maestro se encontraba ante las puertas de la muerte. Así, en Fedón, se dan las primeras aproximaciones de aquello a lo que hoy llamamos "pedagogía de la muerte». Sin pretenderlo explícitamente, la definición platónica según la cual filosofar es aprender a morir junto al ejemplo de Sócrates, que enfrenta con tranquilidad, serenidad y alegría sus últimas horas, representan el mejor ejemplo de presencia de espíritu y de preparación práctica ante la muerte. Sócrates mantiene la misma actitud reposada y tranquila a lo largo del diálogo, actitud que contrasta con el desconcierto general de sus discípulos. El maestro argumenta que mantiene esta actitud puesto que tiene la convicción y la esperanza de una vida después de la muerte donde encontrará dioses, antiguos amigos, etc. Este es uno de los motivos por los cuales mantiene una actitud positiva y alega que esta conducta la deben tener los sabios y filósofos. Además, añade que el buen filósofo es quien cultiva su alma inteligible y el vulgar quien se dedica únicamente al cuerpo (sensible); es decir, como la persona vulgar solo se preocupa del cuerpo y de los gozos sexuales, le aterroriza pensar en la muerte, porque el hecho de destruir su cuerpo le priva de cuanto le es necesario. Por otro lado, el filósofo es quien cultiva las ideas y las desarrolla, 
y entre otros aspectos, es muy consciente que un día u otro llegará la muerte. De este modo, mientras filosofa en vida, se separa de los placeres, deseos y preocupaciones del cuerpo, dedicándose exclusivamente a las cosas que no se adquieren por los sentidos corporales, sino por la mente: la verdad, la sabiduría, la justicia, lo bello, lo bueno, etc. Los platónicos consideran el cuerpo como un obstáculo para conseguir el verdadero conocimiento y, mientras el alma esté ligada, no lo podrán adquirir. Por lo tanto, o nunca se llegará a tener el saber completo o se conseguirá después de morir, en el momento de la separación del cuerpo y el alma.

En definitiva y según Platón, los filósofos se preparan para morir y entienden este momento como el fin del periodo de prueba que lo separa de los bienes invisibles, los cuales persiguen a lo largo de su vida. Sócrates después de toda una vida filosofando, buscando la verdad, invita a sus amigos a continuar haciéndolo para ser recompensados con el saber verdadero. Así, Sócrates empieza a hacer apología de una pedagogía preventiva o previa sobre la muerte, donde es él mismo (quién morirá en breves momentos) quién da estrategias a sus discípulos para enfrentarse a la muerte como la culminación de una vida dedicada al conocimiento. De este modo, Platón (Vives i Solé, 1999) demuestra en el diálogo la tranquilidad y serenidad de Sócrates:

Seguramente la gente no se da cuenta que todos quienes se dedican como es debido a la filosofía no hacen otra cosa que prepararse a morir y a estar muerto. Ahora bien, si esto es verdad, sería algo bien extraño que uno se esforzara durante toda la vida solo en esto y que, llegado el momento [de morir], se revelara contra aquello que hacía tiempo deseaba y preparaba (p. 60).

Empero, a pesar de que los filósofos vivan orientados a la muerte, no significa que tengan que buscar una muerte fácil si antes no han sido capaces de llegar a la verdadera filosofía: abrir el camino de la intelectualidad mediante los diálogos filosóficos para llegar al saber. Para llevarlo a cabo, se debe vivir distanciándose del cuerpo, purificándose para acercarse al máximo a la verdad del saber. Así, Sócrates llega tranquilo al final de su vida, ya que ha vivido de una forma correcta (Pascual, 2008).

Algunos autores piensan que las ideas que refleja Platón en estos diálogos están influenciadas por los pitagóricos de la época, con quienes convivió en su viaje a Sicilia. Los pitagóricos creen que el alma, al separarse del cuerpo, si no está suficientemente purificada, vuelve a la vida después de un tiempo en los «infiernos» (término que en griego no se refiere al infierno cristiano, sino simplemente a la morada de Hades, o lugar de los muertos). Esta idea no es estrictamente pitagórica, dado que tiene su origen en el orfismo (denominados 
también orficopitagóricos). El orfismo también entiende la vida como una preparación para otra vida, rindiendo culto al alma para liberarla y no al cuerpo (Bernabé, 1995). Los órficos creían en la reencarnación después de la muerte mediante la transmigración del alma (metempsicosis). Emplearemos las definiciones de Roque (2009), quién afirma que los órficos entendían la transmigración como el proceso de muerte y reencarnación; por el contrario, la metamorfosis solo afecta a la apariencia en otros cuerpos.

El origen del culto órfico se remite a los sacrificios de Dionisio, que, para expiar su pecado, llegó a la idea de que los humanos estamos condenados a reencarnarnos continuamente dentro de otros cuerpos concebidos como prisiones. Hasta que no se acabe de expiar las culpas, el alma no será liberada de las continuas reencarnaciones. Esta solo puede liberarse mediante los cultos a Dionisio, el mantenimiento de una vida pura y celebrando varios ritos. La concepción de la reencarnación y, en consecuencia, el renacimiento de los muertos es una idea muy común de los pueblos arcaicos (Morin, 1974), como por ejemplo algunos poblados de Malasia, Polinesia, Amerindia, los propios esquimales, etc. Por todo lo mencionado, el orfismo fue el origen de las ideas pitagóricas para, después, influir en Platón, los estoicos y el cristianismo (Bernabé, 1995).

En síntesis, Platón nos dice que no solo nos tenemos que preocupar por el ahora, el carpe diem, sino de todo el tiempo. Sócrates insiste a sus compañeros que su muerte no es una tragedia, ni un final definitivo, sino un tránsito hacia algo nuevo. Acepta su muerte y, de hecho, tiene un final dulce y tranquilo. Por lo tanto, podemos decir que no tiene miedo al emprender este nuevo camino. Después de morir Sócrates, Fedón nos narra la tristeza de los discípulos del maestro y la conclusión a la cual llegaron: Sócrates fue el más sabio y justo de todos los hombres.

\subsection{Abordaje de la dualidad cuerpo-alma en la filosofía}

Las cuestiones sobre el equilibrio entre el alma y el cuerpo han sido debatidas y analizadas a lo largo de la historia de la filosofía. Numerosos filósofos del cariz de Platón (antes mencionado), Aristóteles, Epicuro, Descartes o Nietzsche han abordado el tema. Empero, no todos ellos compartirán la idea expuesta en el Fedón, sino que la pondrán en entredicho y la discutirán. Existen autores que defienden la idea de que el ser humano no es solo un cuerpo, sino que también posee un alma. La pregunta de hacia dónde va el alma después de morir ha sido abordada y discutida desde diferentes ámbitos. Además, ha desencadenado hipótesis de todo tipo, creencias y visiones, las cuales han 
acabado fundando las religiones y organizando civilizaciones (Palacios, 2005). Para ponernos en contexto y resumiendo lo mencionado hasta ahora, Platón, en boca de Sócrates, apuesta por la separación del cuerpo y el alma después de la muerte. Aun así, no lo afirma como una verdad absoluta, sino como una creencia suya. Además, afirma que los sabios y filósofos que cultivan su alma vivirán felices después de la muerte. Por el contrario, los vulgares y los que dedican su vida al cuerpo serán privados de esta felicidad eterna. Esta creencia prueba la antigüedad de la fe de los humanos en un más allá, en una sanción suprema de la ley moral. De este modo, este pensamiento es uno de los principios más universales de la filosofía en nuestra actualidad.

Es importante remarcar la magnitud que ha adquirido el Fedón a lo largo de la historia de la humanidad. Vives i Solé (1999) remarca que:

El Fedón ha sido, probablemente, el diálogo platónico más leído en todos los tiempos, y el que más ha influido sobre la cultura occidental, no solo en el ámbito de la reflexión propiamente filosófica, sino particularmente en el ámbito de las creencias y representaciones populares. [...] Ha trascendido no solo la historia espiritual de su autor, sino también la de su propia época y las estructuras històrico-culturales de las cuales ha surgido (p. 30).

Tal y como afirma Vives i Solé (1999), el Fedón ha creado ciertos pensamientos esenciales de la cultura occidental que han fundamentado los paradigmas que hemos empleado - y continuamos utilizando — en la historia espiritual.

La idea de la separación alma-cuerpo fue revolucionaria en la época de Platón y permanece, actualmente, como fundamento del pensamiento occidental. Las bases filosóficas que aportó Platón sobre la muerte, las adquirieron y compartieron (anterior y posterior a Platón) autores como Pitágoras y Empédocles. Posteriormente, el cristianismo adquirirá de Platón la idea del cuerpo como algo negativo, dado que será fuente de pecado. Aun así, la concepción del alma y de la muerte en Platón no tiene nada que ver con la de los cristianos, a pesar de que la religión adoptó la idea original del filósofo griego. A su vez, la idea de vivir por el cultivo del alma y no del cuerpo por la que apostó Platón ha ejercido gran influencia en el cristianismo. Por ejemplo, solo hay que observar las monjas de clausura, quienes dedican su vida a la espiritualidad con y para Jesucristo.

Por otro lado, hay que decir que numerosos filósofos dialogarán y combatirán la idea de la existencia del dualismo antropológico. En cuanto a los opositores de la existencia del dualismo cuerpo-alma destacamos, en primer lugar, Aristóteles, quien creía que el cuerpo y el alma eran la misma entidad. 
En este sentido, su idea principal era que «el alma no puede ser sin el cuerpo, puesto que el cuerpo forma parte del alma» (Páramo, 2010, p. 563). Incluso así, el pensador defendía que no podía existir un alma sin un cuerpo, a pesar de que sí un cuerpo sin alma, en el sentido estricto del concepto: la muerte del individuo. En este sentido, Aristóteles apuesta por el intelecto humano, quien lo concibe como algo divino y universal (Hernández, 2006). Según Aristóteles, la felicidad humana consiste al equilibrar la virtud, la contemplación y los bienes exteriores. De este modo, equipara y pone al mismo nivel el alma y el cuerpo, aconteciendo siempre el cuerpo necesario como medio para conseguirlo todo. Además, elimina el dualismo entre el mundo sensible y de las ideas o inteligible de Platón, el cual sustituyó por la dicotomía entre materia y forma (De La Cruz, 2002). Así, todo aquello existente está formado de una materia que adopta una determinada forma. En consecuencia, el alma ya no es inmortal, puesto que desaparece cuando el cuerpo muere.

En definitiva, Aristóteles se desmarca de su maestro Platón, dando un giro al pensamiento de la época, ya que apostaba por un monismo corporalista. Por otro lado, encontramos la corriente filosófica del hedonismo (Castro y Chinchilla, 1997), que clásicamente se bifurca en la escuela cirenaica (hedonistas radicales) y los epicúreos (hedonistas racionales). A grandes rasgos, esta doctrina considera que los placeres físicos son la base principal para obtener la felicidad; es decir, identificaba el bien con el placer y el mal con el dolor. Asimismo, si obtenemos el placer material conseguido mediante los sentidos, podremos conseguir el placer espiritual (contrario a la doctrina de Platón). Este planteamiento impide dar el valor necesario a aquello inmaterial, el cual es importante para priorizar el urgente. Por lo tanto, pueden dificultar el duelo de las personas, tal que no se ha valorado suficiente la relación con el ser querido difunto y puede generar algunas consecuencias como las culpabilidades, los arrepentimientos, etc.

En esta línea, Epicuro partió de las ideas platónicas, a pesar de que, tal y cómo dice Torralba (1995), salvó las distancias formales y conceptuales. Epicuro defiende la vida con placeres continuos y racionales como clave para llegar a la felicidad; es decir, no apuesta por los excesos, sino por el satisfacer las necesidades para no sentir dolor tanto en el ámbito físico como en el alma (los placeres pueden tener un sentido sensible o espiritual, como por ejemplo la lectura). Empero, otros filósofos como Schopenhauer afirmaron que el dolor y el sufrimiento son ineludibles y consustanciales a la vida, porque somos voluntad (Mèlich, 2008; Torralba, 1995). Según el mismo autor, el humano no solo sufre porque sabe que morirá, sino que también se hace por «la contingencia, esto es, por la conciencia de que la inexistencia de este 
mundo es tan posible como su existencia» (Mèlich, 2008, p.173). En el ensayo que realizó Mèlich (2008) sobre la antropología del sufrimiento, menciona como Schopenhauer afirma que vivir es sufrir y que, además, Freud afirmó que la mejor arma de combate es el amor (a pesar de que también es una de las mayores causas de sufrimiento). Asimismo, nosotros no creemos en una visión tan negativa de la vida y la realidad; en un sufrimiento continuo. El sufrimiento existe, pero los humanos no nacemos para sufrir siempre, sino para tener experiencias tan positivas como negativas y aprender de las mismas mediante la búsqueda de sentido.

Según la tesis epicúrea, existen deseos naturales y necesarios, y otros que son presuntuosos. Saber distinguir será la clave para elegir placeres en beneficio del cuerpo o el cultivo del alma (ataràxia, la apatheia). Hernández (2006) añade que los epicúreos consideran la muerte como un acontecimiento biológico, externo a la vida humana. En otras palabras, el resultado de la muerte es algo que no afecta a la vida, porque ya no se está vivo. Sin embargo, encontramos otros filósofos contemporáneos como Torralba (2008) quien reniega de la tesis epicúrea, dado que afirma que solo sirve para evadirse de la conciencia de la muerte. Su contraargumento se remite a que, pese a que no hay que preocuparse por la muerte, porque cuando viene el individuo ya no está, no se puede evitar pensar en el sufrimiento que se deja a los seres queridos. Otros, como Arregui (mencionado por Hernández, 2006), también se contraposicionan a la tesis epicúrea mencionada, alegando que la muerte forma parte de la propia vida como límite interno de la misma. Cabe añadir que en la carta que realizó Epicuro a Meneceo proclamó la necesidad de filosofar para no tener miedo al que pueda acontecer. Además, habla del conocimiento de la muerte, no como apuesta por la inmortalidad humana, sino de la conciencia de la finitud como una cuestión de gozo.

En cuanto al duelo prematuro, Epicuro nos dice que es de necios tener miedo a la muerte antes de acontecerla, dado que se tiene un sufrimiento innecesario (posteriormente, Schopenhauer siguió la misma tesis, ya que alegó que si se tiene miedo a la muerte no es por el hecho en sí, sino por las fantasías que genera el humano en torno a la misma).

Montaigne (2010) también hizo su aportación a la pedagogía de la muerte. El filósofo escribió el ensayo Que filosofar es aprender a morir (2010), de clara inspiración platónica, donde dice, entre otras cosas, contra la opinión vulgar, que consiste en no pensar en la muerte, aquello que hace falta es pensar constantemente, a fin de que ya no nos dé miedo ni dolor cuando se presente. No se tiene que esperar a que la muerte nos llegue, la tenemos que esperar en todas partes y así nunca nos sorprenderá. Añade que el individuo que aprende 
a morir, a la vez, también aprende a vivir, porque la conciencia de la muerte es la conciencia de la libertad, en el sentido que nos proporciona libertad, nos libera de temor.

Más tarde, René Descartes (s. XVI-XVII) siguió una línea parecida a la de Platón, apostando por la dicotomía antropológica. Entendía la existencia, por un lado, del pensamiento (res cogitans) y, por otro lado, la materia extensa (res extensa) como dos cosas independientes; es decir, atribuía poca importancia a los sentidos y a todo aquello que pudieran adquirir. Por lo tanto, el filósofo seguía la línea de Platón en el sentido que afirmaba que el verdadero conocimiento no se adquiere con el cuerpo. Llegó a dudar de la fiabilidad de sus sentidos, entre otros aspectos, hasta que llegó la conclusión «Pienso, luego existo» (Descartes, 2010, p. 22). De este modo, se desmarcó de las ideas dogmáticas de la época para descubrir las certezas de forma autónoma (De La Cruz, 2002). Sin embargo, autores como Marinoff (1999) añaden que Descartes olvidó la dimensión interpersonal y social de los humanos a la hora de hacer su conclusión porque cuando muere un ser querido, una parte de nosotros también muere.

Uno de los herederos de Descartes más críticos fue Spinoza quién dijo que no se tenía que reflexionar sobre la muerte, ya que afirmaba que aquello realmente importante era reflexionar sobre la vida y su plenitud (Morin, 1974). Aun así, divergimos de su pensamiento y estamos en la línea de Sócrates y Platón sobre la importancia de pensar con la muerte mientras estemos vivos.

Friedrich Nietzsche (s. XIX-XX) fue el inspirador, en parte, del existencialismo y realizó una ruptura con la filosofía del momento. El existencialismo busca una moral en la ausencia de cualquier autoridad divina, fomentando la autenticidad y la responsabilidad moral (Marinoff, 1999). Nietzsche (2011) realizó una negación de la moral definida hasta entonces. En este sentido, el filósofo llevó a cabo otra interpretación de la muerte que se oponía radicalmente al concepto tradicional.

Uno de los mensajes clave que transmitió, mediante su obra Asi habló Zaratrusta (Nietzsche, 2011), es la muerte de Dios. Osho (2011) añade que la necesidad de creer en un Dios manifiesta la limitación de la conciencia humana. Aun así, este autor contradice a Nietzsche en el hecho de que Dios no ha muerto, porque directamente no ha existido nunca. Siguiendo con Nietzsche, si Dios está muerto, tenemos que vivir sabiendo que no existe ningún Dios. De ahí se saca la consecuencia que, según el pensador, los valores occidentales van cayendo o los hombres los destruimos. Osho (2011) se inclina por el pensamiento de Nietzsche en el sentido que prescindir de Dios posibilita el crecimiento intelectual. En este sentido, se puede observar como el filósofo era 
contrario a la interpretación que realizó el cristianismo sobre el catolicismo, el cual definió como «el platonismo del pueblo» (Derrida, 2006, p. 35).

Nietzsche apela al hecho que la sociedad está viviendo en un momento de nihilismo donde los valores supremos van decayendo despacio. Esta situación repercutió directamente en la concepción que se tiene a las culturas occidentales sobre la muerte. En este sentido, apuesta por una reinterpretación de la muerte. Además, según Nietzsche (2011), Occidente está enfermo por la incapacidad de crear y la debilidad por la angustia ante la muerte. Es decir, la sociedad está corrompida para creer en un "más allá», en definitiva, para creer en una recompensa después de morir. Incluso así, critica el hecho de no hablar y analizar la muerte en sí.

Siguiendo con la idea de la muerte de Dios, Nietzsche la concibe como una rotura de todo aquello que se había afirmado hasta el momento. El filósofo concibe este hecho más que como una tragedia, como una liberación donde los humanos tienen independencia y voluntad de poder. Hay que recordar que Dios representa para los humanos el ideal más supremo.

Nietzsche (2011) denomina superhombre el ideal de hombre, el cual es el único capaz de estimar la vida en toda su complejidad (es decir, aceptando el gozo, pero también el sufrimiento), viviendo intensamente el momento y sin preocuparse por el pasado y el futuro (Torralba, 1995, 2006). En contraposición a las ideas anteriores, Nietzsche apuesta por la concepción de vivir nuestra existencia terrenal de manera intensa y llena, puesto que estamos muriendo cada segundo. Este ideal es llamado dionisíaco, ya que para él tiene una visión vitalista. Según el filósofo, siguiendo este pensamiento podremos morir sin miedo y con tranquilidad puesto que nos espera una eternidad que será mucho mejor que la vida en sí misma.

A su vez, otros filósofos como Sartre (citado por Masreal, 2007) contradicen a Nietzsche (2011) en cuanto que advierten de la angustia que puede provocar el existencialismo por la carencia de explicación existencial. Por el contrario, el mismo autor está de acuerdo en el hecho que la filosofía de Nietzsche apuesta por la responsabilidad de los actos realizados por los seres humanos. Por lo tanto, el humano es capaz de decidir su camino y será responsable de todo aquello que decida.

En definitiva, el filósofo apuesta por una de las teorías de las cuales muchos pedagogos, psicólogos y filósofos actuales afirman y es que hay que tomar conciencia de la finitud y de la temporalidad mundana. De esta forma, se puede vivir en equilibrio si se sustrae dramatismo a la muerte para darle una dimensión más humana. Sabemos que moriremos, pero habitualmente desconocemos el momento en que lo haremos. Por lo tanto, lo que nos espera es incierto, a pesar de que las personas podamos tener ilusión al controlarlo todo. 


\subsection{Actualidad. Estado de la cuestión}

El enfoque platónico, en cuanto a la separación del cuerpo y el alma después de la muerte, sigue perenne en la actualidad. El pensamiento tradicional en Occidente está muy influenciado por la concepción antropológica de Platón. El claro ejemplo es la concepción católica del ser humano, el cual estaría formado por el cuerpo físico y el alma (Derrida, 2006). A su vez, actualmente, la concepción mencionada convive con otras creencias que tienen los individuos para dar respuesta a qué se espera después de la muerte (Poch, 2009, p. 114):

- Perspectiva materialista-humanista: el retorno a la nada, a la oscuridad o una incógnita con un gran interrogante.

- Perspectiva oriental y semática-occidental: un paso para vivir de otra forma para toda la eternidad.

- Perdurar en el recuerdo y el agradecimiento a las personas que nos han querido.

En este sentido, añadimos la perspectiva trascendental, en pro del carpe diem para vivir plenamente. Aun así, autores como Mèlich et al. (2010), Arnaiz (2003) y Esquerda y Agustí (2010) afirman que vivimos en una sociedad donde impera la rapidez, la productividad, el cambio constante, la tecnología omnipotente y la incertidumbre de las relaciones humanas (Bacci, 2014) que son temporales, flexibles y líquidas (Bauman, 2006). Solo nos interesan los resultados a corto plazo y, a veces, confundimos la autorrealización con los hitos materiales. Arnaiz (2003, p. 37) lo define y sintetiza de la siguiente forma: «Descubrimos que las verdades son opiniones, que las seguridades son momentáneas, que la diversidad descubierta y aceptada nos pone frente a una infinidad de conflictos cotidianos». Todo ello ha generado una falsa creencia de control que deja de ser real cuando nos damos cuenta que la muerte no es controlable y tampoco evitable.

La muerte supone sufrimiento y, por lo tanto, nos provoca una emoción que no deseamos. Por este motivo, evitamos hablar de ella, eludiéndola de la vida cotidiana y convirtiéndola en tabú. Este hecho no favorece la elaboración del concepto de muerte. Se continúan banalizando las muertes en tercera persona, aquellas que resultan insignificantes, que han sucedido "pero a mí no». Además, vivimos en una sociedad consumista, donde el apego, la preocupación por el dinero y el consumo de bienes satisfacen nuestras necesidades. Todo ello hace que las personas consideren que no tienen suficiente tiempo 
para dedicarse a uno mismo y crecer espiritualmente como hacían los antiguos filósofos. Por otro lado, invertimos todos nuestros esfuerzos a cuidar y potenciar el cuerpo. Justo es decir que este tipo de pensamiento se basa en lo efímero y temporal, dejando a un lado las cuestiones realmente profundas e importantes.

\section{ConClusiones}

Vivimos en una sociedad donde se suele sobrevalorar el cuerpo y se sufre una pérdida gradual del sentido de la trascendencia a través del cultivo del alma. Desde nuestro punto de vista, pensamos que es necesario vivir intensamente el momento presente, pero tomando conciencia de la necesidad de saber el rumbo que se le quiere dar a la vida. Creemos que es necesario saber qué sentido queremos darle a la vida para poder hacerla única y trascendente.

Los antiguos filósofos apostaban por dejar de lado el cuerpo para dedicarse al alma. Curiosa es la paradoja que nos proporciona la historia del pensamiento del ser humano, ya que actualmente se suele cultivar más el cuerpo que el alma. Hace falta añadir que durante los estudios y experiencia de Kübler-Ross (1994) se constató que las personas con menos formación, vínculos sociales y sofisticación, y los individuos que han sufrido en vida y han encontrado una satisfacción en el ámbito profesional y personal, en general, parecían tener menos dificultad para encarar la muerte. En cambio, las personas con más formación, riqueza material y muchas relaciones interpersonales significativas, les cuesta más afrontar la muerte. Este hecho demuestra que las personas que únicamente cultivan el cuerpo (búsqueda de la riqueza, ambición de bienes materiales, culto al cuerpo, etc.) no tienen la misma predisposición para afrontar la muerte que los individuos que se dedican más al alma (satisfacciones personales y profesionales). Estos últimos podrían ser considerados los «nuevos filósofos», aquellos que, consciente o inconscientemente, han sabido captar la esencia de las enseñanzas más clásicas para afrontar un momento tan decisivo como es la muerte. Es decir, han podido entender y adaptar saberes que, actualmente, nos pueden servir para enfrentarse de una forma diferente.

Se deben aprovechar las estrategias que proporciona la historia de la filosofía y los razonamientos filosóficos (remarcamos los citados en este ensayo) para poder reflexionar, argumentar e indagar sobre el sentido de la vida humana como experiencia única e intransferible. Asimismo, se debe tener en cuenta que la muerte continúa siendo un tabú profesional, ya que es una cuestión educativa de máxima resistencia tal y como apuntaron Rodríguez, Herrán y Cortina (2015). 


\section{REFERENCIAS BIBLIOGRÁFICAS}

Aracil, L. (1998). La mort humana. Barcelona: Empúries.

Arnaiz, V. (2003). ¿Podemos hablar de la muerte en la escuela y en el instituto? Aula de Innovación Educativa, 122, 36-37.

Asensi, J. (2012). Pedagogía de la muerte a través del cine. Indivisa, Boletín de Estudios e Investigación, 13, 218-220.

Bacci, P. (2014). La muerte y el duelo en la hipermodernidad. Recuperado de http://www.querencia.psico.edu.uy/revista_nro13/pilar_bacci.htm

Bauman, Z. (2006). Miedo líquido. La sociedad contemporánea y sus temores. Barcelona: Paidós.

Bermejo, C.J. (2003). La muerte enseña a vivir. Vivir sanamente el duelo. Madrid: San Pablo.

Bernabé, A. (1995). Tendencias recientes en el estudio del Orfismo. Ilu, Revista de ciencias de las religiones, 1, 22-32.

Cantero, M.F. (2013). La Educación para la Muerte. Un reto formativo para la sociedad actual. Psicogente, 16(30), 424-438.

Castro, A. y Chinchilla, M. (1997). Per una pedagogía de la finitud i de l'esperança. Barcelona: Institut Borja de Bioètica.

Cathcart, T. y Klein, D. (2012). Heidegger y un hipopótamo van al cielo. La vida, la muerte y el más allá estudiados con filosofía y mucho humor. Barcelona: Planeta.

Colomo, E. (2016). Pedagogia de la Muerte y proceso de duelo. Cuentos como recurso didáctico. REICE Revista Iberoamericana sobre Calidad, Eficacia y Cambio en Educación, 14(2), 1-15. https://doi.org/10.15366/ reice2016.14.2.004

De La Cruz, M. (2002). El problema cuerpo-mente: distintos planteamientos. Recuperado de: http://platea.pntic.mec.es/ - macruz/mente/cmindex.html

Derrida, J. (2006). Dar la muerte. Barcelona: Paidós.

Descartes, R. (2010). Discurso del método. Madrid: FGS.

Dolto, F. (2005). Parlem amb els infants. Com explicar als nens el sentit de la mort, el valor de la vida dins de la societat i el significat de la festa. Lleida: Pagès Editors.

Esquerda, M. y Agustí, A. M. (2010). El nen i la mort. Acompañar els infants $i$ adolescents en la pèrdua d'una persona estimada. Lleida: Pagès Editors.

Gabarró, D. (2016). Explicar la muerte a niños/as y adolescentes. Recuperado de http://campus.danielgabarro.com/cursos-para-ninos-y-ninas/explicar-lamuerte-a-ninosas-y-jovenes/explicar-la-muerte-a-ninosas-y-jovenes-1 
Girardi, N., San Gil, M. y Santillán, S. (2009). ¿Qué piensan los ninos acerca de la muerte y qué actitudes toman los adultos frente a esto? e-Ecleston. Temas de Educación Infantil, 12(2), 1-7.

Guillén, E., Gordillo, M., Gordillo, M.D., Ruiz, I. y Gordillo, T. (2013). Crecer con la pérdida: el duelo en la infancia y adolescencia. International Journal of Development and Educational Psychology, 1(2), 493-498. https://doi. org/10.17060/ijodaep

Head, B. y Smith, L. (2016). Use of contemporary firlm as a mèdium for teaching an online death and grief course. Journal of Social Work in End-of-Life and Palliative Care, 12, 195-213. https://doi.org/10.1080/15524256.2 016.1201564

Heidegger, M. (1927). Ser y tiempo. Madrid: Trotta.

Hernández, J. (2006). El problema de la muerte en J. Vicente Arregui. Thémat. Revista de Filosofia, 37, 63-73. https://doi.org/10.12795/themata

Herrán, A., González, I., Navarro, M., Bravo, S. y Freire, M. (2000). ¿Todos los caracoles se mueren siempre? Cómo tratar la muerte en educación infantil. Madrid: Ediciones de la Torre.

Herrán, A., González, I., Navarro, M., Bravo, S. y Freire, M. (2001). La muerte: ¿tabú o imperativo educativo? Aula de Innovación Educativa, 106, 62-64.

Herrán, A. y Cortina, M. (2006). La muerte y su didáctica. Manual para Educación Infantil, Primaria y Secundaria. Madrid: Humanitas.

Herrán, A. y Cortina, M. (2007). Introducción a una Pedagogía de la muerte. Educación y Futuro, 17, 131-148.

Herrán, A. y Cortina, M. (2015). Pedagogía radical e inclusiva y educación para la muerte. Salamanca: FahrenHouse.

Huisman-Perrin, E. (2003). La mort explicada a la meva filla. Barcelona: Empúries. Kübler-Ross, K. (1994). Sobre la muerte y los moribundos. Barcelona: Grijalbo.

Kübler-Ross, K. (2013). La mort: una aurora. Barcelona: Luciérnaga.

Mantegazza, R. (2006). La muerte sin máscara. Experiencia del morir y educación para la despedida. Barcelona: Herder.

Marinoff, L. (1999). Más Platón y menos Prozac. Madrid: Ediciones B, S.A.

Masreal, F. (2007). Conviure amb la depressió. Barcelona: Mina.

Mèlich, J.C. (2008). Homo patiens. Ensayo para una antropología del sufrimiento. Ars Brevis, 14, 166-188.

Mèlich, J., Boixader, A. (Coords.), Alguacil, M., Canelles, J., Fons, M., Llovet, J., Palou, J., Poch, C., Segura, A. y Vicente, A. (2010). Los márgenes de la moral. Una mirada ética a la educación. Barcelona: Graó. 
Mèlich, J. M. (2011). Filosofía de la finitud. Barcelona: Herder. https://doi. org/10.2307/j.ctvt $7 \times 7 \mathrm{~d} 8$

Montaigne, M. (2010). Ensayos escogidos. Medellín: Editorial Universidad de Antioquía.

Morin, E. (1974). El hombre y la muerte. Barcelona: Kairós.

Nietzsche, F. (2011). Así habló Zaratustra. Madrid: Alianza Editorial.

Pascual, F. (2008). Esperanza y escatologia: dialogo entra la fe y la razón en Spe salvi. Veritas, 3(18), 47-61.

Orellán, R. (2003). Antropología de la muerte entre lo intercultural y lo universal. Cuidados Paliativos, 9, 305-322. Recuperado de https://academica-e.unavarra.es/xmlui/handle/2454/22768

Osho (2011). Cierra los ojos y lánzate. Escucha el sonido de tu verdad. Barcelona: De Bolsillo.

Palacios, V. (2005). La conciencia de la muerte como conciencia de la vida. Revista de Filosofía Thémata, 34, 155-170.

Páramo, V. (2010). El eterno dualismo antropológico alma-cuerpo: ¿roto por Laín? Thémata. Revista de Filosofía, 46, 563-56. https://doi.org/ $10.12795 /$ themata

Poch, C. (2006). De la vida i de la mort. Recursos per a la familia i l'escola. Barcelona: Claret.

Poch, C. (2009). La muerte nunca falla. Un doloroso descubrimiento. Barcelona: Niberta.

Rodríguez, P., Herrán, A. y Cortina, M. (2015). Educar y vivir teniendo en cuenta la muerte. Reflexiones y propuestas. Madrid: Pirámide.

Roque, M. (2009). Las aves, metáfora del alma. Quaderns de la Mediterrània, 12, 236-244.

Sáiz Ripoll, A. (2010). ¡Un día volveremos a encontrar-nos! Aproximación a la muerte en la literatura infantil y juvenil. Espéculo. Revista de estudios literarios, 45, 1-12.

Torralba, F. (1995). El sofriment un nou tabú? Barcelona: Claret.

Torralba, F. (2006). L'art de saber escoltar. Lleida: Pagès Editors.

Torralba, F. (2008). Planta cara a la mort. Barcelona: Ara Llibres, S.C.C.L.

Valenzano, N. (2015). Educare alla morte per educare allà caducitat e allà vita. Dentro de Pedagogía ante la muerte. Reflexiones e interpretacions en perspectives històrica y filosófica, 1, 205-207.

Vives i Solé, J. (1999). Fedó. Barcelona: Edicions 62. 